Recebido em 09/02/2017. Revisado em 02/05/2017. Aprovado em 02/06/2017.

Editor: Dr. Ivano Ribeiro

Processo de Avaliação: Double Blind Review

e-ISSN: 2359-5876

https://doi.org/10.5935/2359-5876.20170005

\title{
TRANSPARÊNCIA NA GESTÃO PÚBLICA: APLICAÇ̃̃o DA LAI NO MUNICÍPIO DE CASCAVEL SOB A ABORDAGEM DA TEORIA CONTINGENCIAL
}

\author{
Juliano Francisco Baldissera ${ }^{1}$ \\ Clovis Fiirst ${ }^{2}$ \\ Ivan Rafael Defaveri ${ }^{3}$ \\ Everton Luiz Folador ${ }^{4}$
}

\begin{abstract}
RESUMO
Este trabalho teve como objetivo avaliar as ações adotadas pela gestão pública municipal de Cascavel ao efetivo cumprimento da Lei de Acesso à Informação - LAI (Lei $n^{\circ}$ 12.527/2011), quanto à transparência ativa e passiva, sob a abordagem da Teoria Contingencial. Este estudo classifica-se como descritivo, estudo de caso e qualitativo, utilizando-se de entrevistas semiestruturadas. Além disso, utilizou-se como base o Questionário LAI Social (TCE/PR, 2014) publicado por esse Tribunal. O município de Cascavel não cumpre a LAI, estando classificado em $35^{\circ}$ de 69 municípios do ranking, apresentando um grau de transparência de $28,02 \%$. A Teoria Contingencial foi utilizada para observar a sua influência na implementação da LAI. Observou-se que os fatores contingenciais, estratégia e tecnologia, se mostram mais evidentes no desenvolvimento da lei. No entanto, é necessário observar a realidade de cada município, buscando um equilíbrio entre as variáveis, mas devendo ter atenção quanto às variáveis tecnologia e estratégia, as quais são fundamentais à implementação da LAI.
\end{abstract}

Palavras-chave: Transparência. Lei de Acesso à Informação. Teoria Contingencial.

\section{TRANSPARENCY IN PUBLIC MANAGEMENT: APPLICATION OF LAI IN THE MUNICIPALITY OF CASCAVEL UNDER THE CONTINGENCY THEORY APPROACH}

\begin{abstract}
This work aimed to evaluate the actions taken by the municipal public administration of Cascavel to effectively comply with the Law on Access to Information - LAI (Law 12,527 / 2011), regarding active and passive transparency, under a Contingency Theory approach. This study was classified as descriptive, case-study and qualitative, using semi-structured interviews. In addition, the LAI Social Questionnaire (TCE / PR, 2014) published by this Court was used as the basis. The municipality of Cascavel does not fulfill an LAI, is classified in $35^{\circ}$ of 69 municipalities of the ranking, presenting a

\footnotetext{
${ }^{1}$ Mestrando e bolsista da CAPEs do Programa de Pós-Graduação Stricto Sensu em Contabilidade da Unioeste. E-mail: juliano.baldissera@hotmail.com

${ }^{2}$ Mestre em Contabilidade do Programa de Pós-Graduação em Ciências Contábeis - PPGCC da FURB. E-mail: cfiirst@gmail.com

3 Mestrando do Programa de Pós-Graduação Stricto Sensu em Contabilidade da Unioeste. E-mail: ivandefaveri@hotmail.com

${ }^{4}$ Graduado em Ciências Contábeis pela Unioeste. E-mail: evertonfolador@hotmail.com
} 
degree of transparency of $28.02 \%$. The Contingency Theory was used to observe its influence on the implementation of LAI. It was observed that the contingency factors, strategy and technology, are more evident in the development of the law. However, it is necessary to observe a reality of each municipality, which seeks a balance between variables, but that is essential for the variables of strategy and strategy.

Keywords: Transparency. Law of Access to Information. Contingency Theory. 


\section{INTRODUÇÃO}

A cultura da transparência se faz presente no cenário atual do Brasil. Com a implementação da Lei de Acesso à Informação (LAI), Lei Federal no 12.527/2011, houve a regulamentação na gestão pública, que evidenciou de forma indireta os conceitos referentes à transparência ativa e passiva.

Segundo a Controladoria Geral da União [CGU] (2013), transparência ativa pode ser conceituada como a divulgação de informações à sociedade por iniciativa do setor público, independente de requerimento, utilizando principalmente a internet. Contudo, nem todas as informações podem ser viabilizadas de forma ativa, situação a qual surge o conceito da transparência passiva, que caracteriza a divulgação de informações públicas em atendimento às solicitações da sociedade (CGU, 2013).

A transparência na gestão pública é um procedimento a longo prazo, suas mudanças devem ocorrer gradativamente, pois até então a cultura identificada no Brasil era de tratar a informação com sigilo (Alves, 2012). Nesse sentido, a mudança de paradigmas não é fácil de ser trabalhada na administração pública, visto que se faz necessário um período de tempo para que se torne eficaz nas suas concepções.

Assim como acontece no ambiente privado, existem fatores contingenciais que também podem influenciar na administração. Nesse sentido, foi utilizada a Teoria Contingencial para explicar quais fatores afetam a implementação da LAI no setor público municipal.

$\mathrm{Na}$ análise dos fatores contingenciais que podem afetar a administração de uma entidade, algumas variáveis têm maior destaque, são elas: ambiente, tecnologia, estrutura organizacional, porte e estratégia. Essas são as variáveis que esse estudo buscou identificar no ambiente público municipal em relação à implementação da LAI. A partir da evolução vista na administração pública, percebe-se a mudança de concepções adotadas por esta - desde o modelo patrimonial, depois para o estilo burocrático e, atualmente, o gerencial. Dessa forma, assim como a forma de administrar mudou, também as contingencias que afetam a administração são outras. A informação tratada como pública é uma das características adotadas na estratégia da administração pública gerencial para a formação de um novo Estado, que se caracteriza, basicamente, por meio da administração a priori, ou seja, o controle por meio de resultados.

Desde a vigência da LAI, a partir de 16 de maio de 2012, os municípios não vêm cumprindo de forma efetiva com o que está disposto na lei, conforme é visualizado pelas auditorias realizadas pelos órgãos do controle externo, pois ainda existe muita dificuldade por parte desses em disponibilizar as informações à sociedade, com agilidade, de forma transparente, clara e em linguagem de fácil compreensão.

Entretanto, mesmo com a regulamentação, com a elaboração de regras, de diretrizes, de deveres e de direitos para o acesso à informação, o que é visto, atualmente, é que os municípios não vêm seguindo o que está disposto na lei (Paraná, 2014). Nesse sentido, esse trabalho justifica-se pela necessidade da avaliação da transparência ativa e passiva no município de Cascavel, no Paraná. Essa pesquisa busca proporcionar uma oportunidade para verificar o efetivo cumprimento da LAI, como a gestão pública do município está trabalhando em relação à transparência e, além disso, de que forma as políticas públicas adotadas estão direcionadas ao desenvolvimento da transparência na cidade de Cascavel.

A pesquisa é relevante por levantar evidencias através da teoria contingencial, no sentido de descobrir os fatores dificultadores que afetam a implementação da LAI em municípios, visto que os municípios são responsáveis por vários serviços finalísticos à sociedade, e recebem de forma "topdown" (de cima para baixo) a implantação de procedimentos.

Dentre as pesquisas realizadas na área, destacasse a do Professor DaMatta (2011), onde percebese que há grande movimento em curso de abertura e conscientização sobre a transparência no setor público. Tem-se preocupação com o mau uso das informações pelo público, com a má interpretação ou com a descontextualizacão das informações, bem como com as práticas adotadas na gestão de informações, as quais são bastante diversificadas, observando-se, ainda, que o poder executivo já dispõe de sistemas de informações e bancos de dados modernos, processos digitalizados, sistemas e vários 
canais de comunicação com a sociedade. No entanto, essa não é uma característica observada em todos os municípios, uma vez que, para outros, essa implementação ainda está no papel e, além disso, nota-se a preocupação quanto ao custo que envolve a efetivação do acesso à informação, principalmente com pessoal qualificado, destinado exclusivamente para a manutenção do atendimento de solicitações e de aspectos contingenciais.

Outro estudo é o de Paiva e Zuccolotto (2009), que buscaram identificar quais são os fatores determinantes da transparência na gestão pública dos municípios brasileiros, evidenciando o nível de transparência fiscal, dividindo em alto, médio e baixo, obtendo os seguintes percentuais, respectivamente: $9,71 \%, 19,88 \%$ e 70,41\%. Fica exposto, portanto, um baixo índice de transparência nos municípios, onde apenas $9,71 \%$ conseguiram se enquadrar no nível alto de transparência, conforme os parâmetros da pesquisa.

Entretanto observa uma lacuna de pesquisa que necessita ser explorada no sentido de contribuir para o entendimento dos fatores contingenciais que podem afetar a implantação da LAI e ainda contribuir com a continuidade da pesquisa na área temática com o uso de teorias organizacionais.

Para o desenvolvimento dessa pesquisa foi estabelecido como problema de pesquisa: como o municipio está cumprindo com as obrigações dispostas na Lei de Acesso à Informação, quanto à Transparência Ativa e Passiva, e quais os fatores contingenciais afetam a implementação da Lei? Dessa forma, esta pesquisa tem por objetivo avaliar as ações adotadas pela gestão pública municipal ao efetivo cumprimento da Lei de Acesso à Informação, quanto à Transparência Ativa e Passiva, sob a abordagem da Teoria das Contingências.

Através desse objetivo buscará observar a realidade do município quanto à observância da Lei $\mathrm{n}^{\mathrm{o}} 12.527 / 2011$, tendo em vistas os cinco fatores contingenciais que afetam na implementação da lei.

O presente estudo está delimitado a cidade de Cascavel, observando-se tão somente a Prefeitura do município, órgão do poder Executivo. Para avaliar a transparência ativa foi observado o portal eletrônico do município, enquanto que para avaliar a transparência passiva observou-se documentos como a legislação, procedimentos internos e respostas aos pedidos de informação. Os aspectos contingenciais foram analisados tendo em vista as entrevistas com os gestores públicos selecionados. A pesquisa foi realizada nos anos de 2014 e 2015.

\section{REVISÃO DA LITERATURA}

\subsection{Acesso à informação}

O acesso à informação pública tornou-se evidente a partir da publicação da Constituição Federal (1988), por meio do artigo $5^{\circ}$, inciso XXXIII, em que foi garantido a todos os cidadãos:

todos têm direito a receber dos órgãos públicos informações de seu interesse particular, ou de interesse coletivo ou geral, que serão prestadas no prazo da lei, sob pena de responsabilidade, ressalvadas aquelas cujo sigilo seja imprescindível à segurança da sociedade e do Estado (Constituição, 2008, p. 17).

Portanto, a partir da Constituição Federal (1988), foi possível observar que o país buscava caminhar em direção a uma cultura que fortalecesse a transparência da gestão pública, em que fosse possível o controle social pelos cidadãos a partir das informações públicas da União, dos Estados, do Distrito Federal e dos Municípios. O legislador buscou retomar o termo do acesso à informação em outro momento da Constituição, ainda no artigo $5^{\circ}$, inciso XIV, "é assegurado a todos o acesso à informação e resguardado o sigilo da fonte, quando necessário ao exercício profissional".

$\mathrm{O}$ acesso à informação pode ser entendido como um direito básico de todo o cidadão, sendo, portanto, dever do governo que as informações existentes sejam compreensíveis pelos cidadãos para que a participação destes seja possível no governo, isto é, para que ocorra o controle social (Stiglitz, 1999). Nesse sentido, não basta a apresentação de dados para os cidadãos, é necessário que esses sejam compreensíveis e passíveis de utilização pelo cidadão. 
A transparência, enquanto prática de governança pública, deve representar toda a atividade realizada pelos gestores públicos, de tal forma que possibilite aos cidadãos o acesso e a compreensão daquilo que está sendo realizado pelos gestores governamentais (Cruz, Silva, \& Santos, 2009).

De acordo com o manual da Organização para a Cooperação e Desenvolvimento Econômico (OCDE), a informação como uma forma de participação do cidadão na formulação das políticas públicas é o que deve prevalecer, portanto, é imprescindível que esses assumam um papel na formulação de políticas (OCDE, 2002). A participação dos cidadãos, aliada à melhoria da transparência governamental, tende a reduzir consideravelmente a assimetria de informação e, consequentemente, os abusos cometidos por autoridades governamentais.

A informação pública é uma necessidade para a realização de um governo popular que realmente atende aos interesses do povo e visa desenvolver as concepções do new public management.

\subsection{Teoria Contingencial}

Diante das incertezas que podem ser observadas na gestão de uma empresa é possível identificar diversos fatores que interferem a tomada de decisões de cada entidade, sendo, portanto, pressupostos da Teoria Contingencial. Guerra (2007) apresenta que a melhor forma de gerir as empresas requer profunda análise das características das situações que se apresentam para elas.

A Teoria da Contingência enfatiza que nas organizações tudo é relativo, tudo depende de algo (Chiavenato, 2004). Essa teoria diz que não existe a maneira ideal de se administrar ou a melhor escolha, pois o ambiente interno e externo afeta diretamente nessas escolhas, de modo que seja possível observar diversas variáveis a serem consideradas e tendo em vista todos esses cenários, a empresa deve buscar adaptar a sua realidade às escolhas e optar pelo rumo que seja mais vantajoso.

Esta teoria considera que a administração será tanto mais eficaz quanto maior a capacidade de seus membros em escolher a forma adequada a cada tipo de situação que seja apresentada (Chiavenato, 1979). Por meio desse pressuposto, é possível observar que as contingências não são presentes tão somente na gestão da entidade privada, ela também está inserida na gestão da administração pública, tendo em vista que também precisa fazer escolhas e dar continuidade em suas políticas (Molinari \& Guerreiro, 2004).

No estudo dessas contingências, identifica-se diversas variáveis que influenciam nas escolhas de cada entidade, os quais são diferentes para cada tipo de organização. A administração pública, por exemplo, encontra diferentes fatores que a afetam, mas também apresenta fatores em comum com entidades privadas. Dessa forma, alguns fatores são comumente elencados na literatura, como por exemplo, o ambiente, a estratégia, o porte, a tecnologia, a estrutura e os estágios do ciclo de vida organizacional

Os fatores contingenciais podem ser variáveis tanto internas, como, por exemplo, a estrutura, o tamanho e a estratégia, quanto externas, como a globalização dos mercados, os avanços tecnológicos, o aumento de concorrência e a complexidade de arranjos produtivos que podem modelar características específicas da empresa em determinado momento (Junqueira, 2010). Esses fatores são identificados de maneira interna e externa à empresa a partir de cada realidade, alterando-se com o passar do tempo e dos diversos cenários econômicos.

Na Teoria Contingencial tem-se o conceito de adequação, que se traduz na ideia de buscar analisar a adequação entre os contextos ambientais e a estrutura organizacional, tendo como premissa a ideia de que quanto maior a adequação, melhor será o desempenho (Guerra, 2007).

No Brasil, a implementação da Lei de Acesso à Informação é um desafio enfrentado pelos entes políticos, pois a realidade de cada município, estado ou país, é diferente. Portanto, as suas dificuldades não são as mesmas, mas, ainda assim, observa-se fatores comuns entre eles, os quais podem ser compartilhados e, por isso, é importante realizar o estudo da teoria contingencial aplicado a entidades públicas.

Chiavenato (2004) postula que, como a organização é um sistema aberto, ela mantém transações e intercâmbio com seu ambiente. Isso faz com que tudo que ocorre externamente no ambiente passe a influenciar internamente o que ocorre na organização. Portanto, essa realidade é, de certa forma, 
observada na administração pública, ao passo que a sociedade exige políticas públicas eficientes e efetivas, bem como o cenário econômico de um país afeta a gestão dessa administração.

Diferentemente do fator contingencial ambiente, a estrutura é um fator controlável pela empresa. Essa variável é associada, normalmente, ao grau de descentralização da organização. Dessa forma, um maior grau descentralizador conduz a uma estrutura orgânica, já um menor grau gera uma estrutura mecânica.

Assim como a estrutura, o fator interno estratégia é, também, controlável. Na análise desse fator, autores como Porter (1986) e Mintzberg (1995) defendem duas classificações: estratégias conhecidas como genéricas, abordadas na Teoria da Administração, e outras denominadas de grupos estratégicos de empresas da Economia Industrial. Sendo assim, é importante observar o modelo atual da administração pública brasileira, o gerencial, e buscar conhecer e adaptar as teorias mencionadas nesse modelo atual de gestão.

Outra variável que pode ser considerada é o porte. No Brasil é comum avaliar essa variável de acordo com o faturamento operacional bruto da entidade (Espejo, 2008). Dessa forma, a partir desses dois entendimentos, seja pelo número de funcionários ou pelo faturamento, tem-se as realidades observadas nas entidades públicas. $\mathrm{O}$ faturamento, mesmo que não esteja intrinsicamente relacionado à finalidade dessas entidades, também é observado a partir das receitas de tributos, de contribuições, patrimoniais, entre outras.

A tecnologia também se apresenta como um fator contingencial, a qual pode ser analisada sobre dois aspectos: o primeiro avalia a tecnologia da informação presente na empresa e o segundo analisa a tecnologia aplicada na manufatura dos produtos da empresa (Espejo, 2008). No contexto da gestão da coisa pública percebe-se que a aplicação se dá sobre o primeiro aspecto, principalmente, pois é por meio da tecnologia da informação que a entidade pública traduz o seu dia a dia.

Junto à necessidade de dar transparência às informações, há a necessidade de meios eficazes que instrumentalizem esse processo de disponibilização desses dados. Dessa forma, a tecnologia de informação é de suma importância para facilitar a implementação da LAI, com a disponibilização imediata das informações por meio da internet, por exemplo.

Em outra vertente, Chiavenato (2012) estabelece que a tecnologia se desenvolve nas organizações por meio de conhecimentos acumulados e desenvolvidos sobre o significado e a execução de tarefas e por suas manifestações físicas, constituindo um complexo de técnicas usadas na transformação dos insumos recebidos pela empresa em resultados.

Tendo em vista o desafio da implementação de uma gestão transparente, é importante observar as melhores práticas diante desse contexto pelo qual estão inseridos os entes políticos. Assim, a Teoria Contingencial apresenta os fatores que surgem diante dessas incertezas e ajuda na escolha das melhores decisões para essas mudanças. Para tanto, se faz necessário o estudo e a compreensão dessa teoria pelos gestores públicos na implementação da transparência, facilitando a compreensão das variáveis envolvidas para, então, reconhecer os dispêndios necessários a essas mudanças.

\section{METODOLOGIA}

Os objetivos dessa pesquisa exigiram adotar um delineamento de pesquisa adequado. Assim, essa pesquisa classifica-se como descritiva, pois tem por finalidade observar, analisar e descrever as concepções da transparência e da teoria contingencial obtidas com este estudo, corroborando com o entendimento de Yin (2002). Os procedimentos adotados para essa pesquisa foram o de um estudo de caso, já que se analisou a prefeitura do município de cascavel. Devido à complexidade e aprofundamento necessário nas informações coletadas, utilizou-se a abordagem qualitativa para explorar o problema de pesquisa e descrever os resultados (Richardson, 1999).

Os resultados obtidos na pesquisa foram descritos conforme as características do tema, as disposições da LAI e a abordagem contingencial. Esse estudo tem como base a pesquisa do Tribunal de Contas do Estado do Paraná (Paraná, 2014), que apresentou uma pesquisa em relação aos níveis de transparência nos municípios do estado, incluindo, portanto, a cidade de Cascavel.

Optou-se por esse modelo devido às características da pesquisa, pelo fato de que foi aplicado o 
estudo no município de Cascavel - PR, em que se observou as características que esse município apresenta quanto à Lei Federal $\mathrm{n}^{\mathrm{o}} 12.527 / 2011$ e aos aspectos contingenciais que afetam a sua implementação, onde permitiu reconhecer a realidade e avaliar as ações do município em observância a LAI e aos aspectos relacionados à abordagem contingencial.

Por meio do reconhecimento de que a Lei Federal $n^{0}$ 12.527/2011, que trata sobre o acesso à informação é uma exigência recente e que fica evidente que o processo de implementação é em longo prazo, estabeleceu-se como proposição com base nos estudos Paiva e Zuccolotto (2009), DaMatta (2011) e Paraná (2014): o município de Cascavel não cumpre de forma efetiva com as exigências da lei, principalmente nos aspectos relacionados à transparência passiva, devido às deficiências contingenciais relacionados à estrutura organizacional e à tecnologia de informação.

Como instrumentos de pesquisa optou-se pela utilização de entrevista semiestruturada, de forma que fosse possível obter contribuições positivas para essa pesquisa qualitativa e responder à questão de pesquisa e alcançar os objetivos específicos. Esse tipo de entrevista se caracteriza por um conjunto de perguntas ou questões definidas em um roteiro flexível em torno de um ou mais assuntos do interesse de uma pesquisa para elucidação do objeto (Trivinos, 1995). Esta pesquisa utilizou o software NVIVO $11 \circledR$ para auxiliar na análise das entrevistas, sendo elaborados mind maps que evidenciaram os principais resultados para cada um dos fatores contingenciais.

Portanto, a utilização deste instrumento foi útil para coletar a percepção do Secretário de Assuntos Jurídicos e dos agentes responsáveis pelos setores de informática e do controle interno, sujeitos envolvidos com a transparência no município, buscando observar os procedimentos adotados, aspectos contingenciais, planejamentos e concepções adotadas pelo poder executivo.

Para a análise da Transparência foi utilizado o "Questionário LAI Social - Avaliação da Métrica dos Sítios e Portais dos Municípios", com métrica própria do TCE-PR, utilizado na pesquisa do LAI SOCIAL, que avaliou 69 municípios do Paraná. Esse questionário resultou no ranking da LAI e contou com 35 questões fechadas, divididas em três grupos: Transparência Ativa, Transparência Passiva e Requisitos do Site (Paraná, 2014).

Dessa forma, visualizando os níveis de transparência obtidas por meio do Questionário LAI Social e da entrevista aplicada, buscou-se, também, observar os aspectos contingenciais que afetam a implementação da LAI no município, buscando, portanto, apresentar uma pesquisa que não se restringisse tão somente na transparência do município, avaliando-a sob a abordagem da Teoria Contingencial.

Sob este enfoque, elaborou um constructo (Quadro 1) em que é possível observar as categorias de análise, definições, aspectos analisados e autores que fundamentaram cada análise.

Quadro 1. Constructo

\begin{tabular}{|c|c|c|c|}
\hline $\begin{array}{c}\text { Categoria de } \\
\text { análise }\end{array}$ & Definição & Aspectos analisados & Autores \\
\hline $\begin{array}{l}\text { Transparência } \\
\text { Ativa }\end{array}$ & $\begin{array}{l}\text { A divulgação de informações à } \\
\text { sociedade por iniciativa do próprio } \\
\text { setor público, que se antecipa e torna } \\
\text { pública as informações, independente } \\
\text { de requerimento, utilizando } \\
\text { principalmente a Internet. }\end{array}$ & $\begin{array}{l}\text { Regulamentação da LAI; } \\
\text { Informações mínimas } \\
\text { obrigatórias. }\end{array}$ & $\begin{array}{l}\text { Lei } n^{\circ} 12.527 \\
(2011) ; \text { CGU } \\
(2013) ; \text { Alves } \\
\text { (2013) }\end{array}$ \\
\hline $\begin{array}{l}\text { Transparência } \\
\text { Passiva }\end{array}$ & $\begin{array}{l}\text { É a divulgação de informações } \\
\text { públicas em atendimento às } \\
\text { solicitações da sociedade. }\end{array}$ & $\begin{array}{l}\text { Serviço de Informação ao } \\
\text { Cidadão (virtual e presencial); } \\
\text { Procedimentos de atendimento } \\
\text { às solicitações. }\end{array}$ & $\begin{array}{l}\text { Lei n }{ }^{\circ} 12.527 \\
(2011) ; C G U \\
(2013)\end{array}$ \\
\hline
\end{tabular}




\begin{tabular}{|c|c|c|c|}
\hline $\begin{array}{c}\text { Categoria de } \\
\text { análise }\end{array}$ & Definição & Aspectos analisados & Autores \\
\hline Ambiente & $\begin{array}{l}\text { A organização é um sistema aberto, } \\
\text { ela mantém transações e intercâmbio } \\
\text { com seu ambiente, isso faz com que } \\
\text { tudo que ocorre externamente no } \\
\text { ambiente passe a influenciar } \\
\text { internamente o que ocorre na } \\
\text { organização. }\end{array}$ & $\begin{array}{l}\text { Órgãos de controle externo; } \\
\text { cobrança da sociedade } \\
\text { organizada e geral; momento } \\
\text { político e econômico; restrições } \\
\text { legais; necessidades da } \\
\text { população. }\end{array}$ & $\begin{array}{l}\text { Chiavenato } \\
(2004)\end{array}$ \\
\hline Tecnologia & $\begin{array}{l}\text { Conhecimento acumulados e } \\
\text { desenvolvidos, constituindo um } \\
\text { complexo de técnicas usadas na } \\
\text { transformação dos insumos em } \\
\text { resultados. }\end{array}$ & $\begin{array}{l}\text { Tecnologia atual; softwares e } \\
\text { hardwares utilizados; fluxo de } \\
\text { informações; atualização das } \\
\text { informações; integração e } \\
\text { compartilhamento de dados; } \\
\text { qualidade informação; } \\
\text { profissionais capacitados. }\end{array}$ & $\begin{array}{l}\text { Espejo (2008); } \\
\text { Chiavenato } \\
(2012)\end{array}$ \\
\hline Estrutura & $\begin{array}{l}\text { Associada ao grau de descentralização } \\
\text { da organização }\end{array}$ & $\begin{array}{l}\text { Descentralização } \\
\text { cargos/funções; } \\
\text { projetos/programas/ações; } \\
\text { contratação e exonerações; } \\
\text { estrutura atual. }\end{array}$ & $\begin{array}{l}\text { Porter }(1986) \\
\text { Mintzberg } \\
(1995)\end{array}$ \\
\hline Estratégias & $\begin{array}{l}\text { Conjunto de mudanças competitivas e } \\
\text { abordagens que os gestores públicos } \\
\text { executam para atingir o melhor } \\
\text { desempenho da instituição. }\end{array}$ & $\begin{array}{l}\text { Estratégias atuais; projetos } \\
\text { desenvolvidos; boas-práticas; } \\
\text { efeitos das estratégias; interesse } \\
\text { público. }\end{array}$ & $\begin{array}{l}\text { Porter }(1986) \text { e } \\
\text { Mintzberg } \\
(1995)\end{array}$ \\
\hline Porte & $\begin{array}{l}\text { Relação de tamanho de um município } \\
\text { considerando a receita bruta e seus } \\
\text { habitantes. }\end{array}$ & $\begin{array}{l}\text { Características municípios } \\
\text { maior/menor porte. }\end{array}$ & Espejo (2008). \\
\hline
\end{tabular}

Fonte: Os autores (2016)

As limitações que podem prejudicar os resultados da pesquisa são observadas nas características das informações, nos dados disponíveis, nas condições operacionais e no viés de interesse dos entrevistados. Algumas das limitações para o presente estudo pode ser a característica das informações, metodologia adotada, dados disponíveis, condições operacionais e viés de interesses dos entrevistados.

Portanto, observa-se que algumas dessas limitações podem prejudicar os resultados da pesquisa, no entanto, buscará apresentar evidências confiáveis que possam contribuir com o tema. Dessa forma, reconhecendo as limitações fará uso das entrevistas semiestruturadas para coleta e da análise de dados, fazendo a devida triangulação com o Questionário LAI Social, documentos, observação de campo e a própria entrevista, para buscar mitigar essas lacunas.

\section{APRESENTAÇÃO DOS RESULTADOS}

\subsection{Transparência}

\subsubsection{Transparência ativa}

A regulamentação da LAI nos municípios é uma exigência obrigatória destes entes políticos, com esta regulamentação é que será possível dar viabilidade a esse direito. O município de Cascavel ainda não cumpre com essa exigência. Uma das justificativas por ainda não ter elaborado se deve ao fato de que ainda é necessário preparar melhor a estrutura para atender a essa demanda. O entrevistado apresenta que está buscando preparar um setor para atendimento, funcionários capacitados e treinamento necessário.

As informações dos órgãos e das entidades públicas devem ser disponibilizadas a todos, independentemente de solicitação, de modo imediato. $\mathrm{O}$ art. $8^{\circ}$ da Lei n ${ }^{\circ}$ 12.527/2011 estabelece que "é 
dever dos órgãos e entidades públicas promover, independentemente de requerimentos, a divulgação em local de fácil acesso, no âmbito de suas competências, de informações de interesse coletivo ou geral por eles produzidas ou custodiadas".

Fica claro, portanto, que as informações de sua competência devem estar disponíveis em local de fácil acesso, buscando atender ao princípio da publicidade e de modo que não dificulte o acesso. $\mathrm{Na}$ divulgação dessas informações do art. $8^{\circ}$, a própria LAI, nos incisos do $\S 1^{\circ}$ desse artigo, estabelece as informações mínimas que devem ser divulgadas, como registro de competências, estrutura institucional, repasses, transferências, despesas, receitas, licitações, contratos, dados gerais para o acompanhamento de programas, ações, projetos, obras, entre outras.

Tendo em vista essas exigências da lei, no município observou-se que quanto ao conteúdo institucional, ações e programas, convênios, termos aditivos de contratos, diárias, relatórios de viagem não estão sendo apresentadas de forma adequada no portal do município. No entanto, quando as informações relacionadas ao acompanhamento da gestão fiscal, financeira e orçamentária, receitas e despesas, licitações e contratos estão sendo divulgadas.

No portal do município não é disponibilizado a remuneração, subsídios, auxílios, ajuda de custo e outras vantagens recebidas pelos seus servidores, e não divulga-se em detalhes os formatos utilizados para a estruturação da informação, nem garante autenticidade das informações disponíveis para acesso.

Dos itens avaliados pelo Questionário LAI Social observa-se que o município não atende muito dos quesitos apresentados, se mostrando, portanto, deficiente quanto ao cumprimento da transparência ativa, principal meio de acesso a informações pelos cidadãos, e também em relação à transparência passiva.

Primeiramente, umas das medidas necessárias que o município deve adotar é a regulamentação da LAI, o que pode mudar a realidade da gestão pública. Percebe-se que o município vem atendendo às disposições quanto ao conteúdo institucional, conteúdo financeiro e orçamentário, informações de licitações e ações programas, apresentando link que remetem a cada um desses itens. No entanto, em muitos desses casos as informações se mostram deficientes, não apresentando da forma que deveria ser dada, de modo disperso, de difícil acesso e pouco detalhada.

Quanto às informações mínimas, à identificação das informações relevantes sobre processos licitatórios e aos contratos administrativos, observa-se que elas são apresentadas no portal da transparência, bem como as informações relevantes sobre acompanhamento de gestão fiscal/financeira e orçamentária do município. Nesse sentido, observa-se que não existe link específico para o Portal de Acesso à Informação, o entrevistado justifica que é devido à questão de estrutura e do contrato com empresa terceiriza de tecnologia, que impossibilita a implantação efetiva do acesso à informação no site do município.

Portanto, conclui-se que a informação base está no portal da transparência, porém, não está em linguagem acessível. A ferramenta de busca está ineficiente. O sistema depende da empresa terceirizada, porém demora para fazer as adequações e as atualizações necessárias. Isso demonstra que a cultura do sigilo ainda é um desafio a ser superado.

\subsubsection{Transparência passiva}

A transparência passiva é fundamentada na Lei ${ }^{\circ} 12.527 / 2011$ que é caracterizada quando a informação não está disponível de forma imediata, sendo necessária a requisição por meio de pedido ao órgão ou à entidade pública. $\mathrm{O}$ art. $9^{\circ}$, dessa lei, traz que é necessário a criação de um Serviço de Informação ao Cidadão (SIC).

Percebe-se, portanto, a necessidade de criação de um serviço de informações ao cidadão, que nada mais é senão uma ferramenta de viabilizar o acesso e formular um pedido. Portanto, o SIC pode ser de modo virtual (e-SIC) ou presencial, a diferença dos dois é que o primeiro se dá por meio da formulação de um pedido com o auxílio da internet e o segundo por meio do próprio órgão ou entidade, in loco.

Quanto ao e-SIC, a prefeitura de Cascavel não dispõe de uma ferramenta adequada para solicitar um pedido de informação. No entanto, apesar de não ter uma ferramenta legítima para o pedido online, 
o entrevistado afirmou que atualmente esses pedidos são feitos por meio do "Fale Conosco" e o "Fale com o Prefeito". No entanto, o Tribunal de Contas não considera esse meio adequado para dar o acesso a informações.

Dessa forma, entende-se que o e-SIC não está disponível, não é de fácil acesso independente do estágio de navegação do usuário, não tendo orientação de como obter a informação em meio físico, não apresenta formulário específico para a formulação do pedido. Não atende as exigências da lei.

Quanto ao SIC - presencial, a prefeitura de Cascavel apresenta local próprio para recepcionar os pedidos de acesso à informação. O pedido, no município, é feito por meio do Protocolo Geral situado no paço municipal, o qual possui formulário próprio para os pedidos de acesso à informação. Ainda que este não seja o mais adequado, pois não fica claro que é através desse local que é possível realizar um pedido de informação.

Foram realizados dois pedidos de informações, um no meio presencial e outro através do site do município. Observou-se que a prefeitura de Cascavel respondeu aos dois pedidos dentro do prazo, atendendo, portanto, às exigências da lei, que estabelece que a informação deve estar disponível de modo imediato, ou quando necessário, dentro do prazo de 20 dias, podendo ser prorrogados por mais dez.

Nesse caso, percebeu-se que os pedidos presenciais na prefeitura estão melhor formalizados, no entanto, o pedido online ainda merece atenção pelo município, tendo em vista que ainda se mostra deficiente. Portanto, no que diz respeito à transparência passiva, ela se mostra defíciente em diversos momentos, principalmente no sistema de informação aos cidadãos, tanto o presencial quanto o eletrônico.

Em relação às dificuldades para implantação da Lei de Acesso à Informação, alega-se, basicamente, falta de tecnologia de informação necessária para viabilizar o acesso, em que seria possível por meio de um sistema operacional apropriado. Outra justificativa é a falta de pessoal qualificado que possa atender a esses pedidos, devido à complexidade que apresentam, a prefeitura ainda precisa de pessoal específico para esse trabalho, pois dos muitos que já estão trabalhando com encargo, estão com excesso de carga de trabalho.

Os dados obtidos demonstram que a transparência passiva se mostra mais deficiente que a ativa, os gestores devem dar importância ao critério de transparência, pois em muitos casos essa é a única forma de permitir o acesso à informação. Esta conclusão corrobora com a proposição dessa pesquisa, a qual postulava que a transparência era a mais deficiente. Os gestores públicos devem dar importância a essa forma de transparência, pois em muitos casos essa é a única maneira de acesso à informação.

Tendo em vista o ranking geral publicado pelo TCE/PR (Paraná, 2014), que avaliou 69 municípios do estado do Paraná quanto à transparência ativa e passiva, Cascavel ficou na posição $35^{\circ}$ do ranking, atingindo um grau de transparência de $28,02 \%$, uma nota que pode ser considerada baixa para os parâmetros da lei. Essa posição e o grau de transparência do município reflete o que foi visto no Questionário LAI Social, uma vez que, em poucas ocasiões, o município conseguiu atender às exigências dispostas na lei.

Além de Cascavel é preciso observar a situação crítica dos outros municípios, somente três cidades conseguiram atingir uma média de transparência acima de 50\%. Esse resultado pode ser característica de que o interesse público dos gestores não está alinhado com a necessidade de implementar a lei. Mas também pode ser devido à falta de clareza estabelecida na Lei $\mathrm{n}^{\circ}$ 12.527/2011, a qual estabelece que a informação deve ser pública na maioria dos casos, mas não informa como deverá ser feito e, em alguns momentos, foge do que pode se considerar razoável.

Estes resultados corroboram com os estudos de Paiva e Zuccolotto (2009) e DaMatta (2011), visto que a transparência se mostrou frágil quanto a sua efetivação, não se percebeu as práticas adotadas na gestão das informações, e ainda que o poder executivo tenha sistemas de informações e banco de dados, não estão atendendo aos requisitos de divulgação e transparência de forma adequada, resultando em um índice baixo de transparência.

A teoria contingencial pode explicar algumas variáveis que afetam o processo de implementação da LAI, uma vez que considera que o ambiente, a tecnologia, a estrutura, a estratégia e o porte são fatores que afetam a tomada de decisão de um gestor, ou então, as próprias mudanças. 


\subsection{Teoria Contingencial}

\subsubsection{Ambiente}

Os órgãos de controle externo, a sociedade em geral e a sociedade organizada tem ganhado força na cobrança por transparência, principalmente os tribunais de contas, poder legislativo e ministério público. A sociedade em geral está tomando conhecimento do seu direito e está participando mais na gestão pública do município, mas ainda não participa tanto em audiências públicas e na prestação de contas do município à câmara legislativa. A sociedade organizada, normalmente, atua mais que os próprios cidadãos, os observatórios sociais se mostram mais presentes nesse caso

O cenário econômico e político atual vem afetando de maneira direta e indireta o município. A crise econômica que afeta o mundo, também se mostra presente no Brasil, interferindo nos repasses que vinham sendo feitos pelos órgãos federais ao município, o que limita a atuação municipal, dificultando o atendimento a todas as demandas, inclusive no que diz respeito à implementação da lei de acesso à informação.

Um dos entrevistados afirma que: "os recursos são limitados, no entanto as necessidades são ilimitadas". Há a preocupação de aplicação de forma adequada dos recursos recebidos, buscando-se sempre fazer bom uso do dinheiro público, mas nem sempre esses valores são suficientes.

Considerando o fator contingencial ambiente, observou-se que a atuação dos órgãos de controle externo, população e a sociedade organizada no controle da gestão pública, afetando a implementação da LAI, fazendo com que haja uma preocupação por parte dos gestores e de autoridades públicas com a transparência, o que tem se mostrado como uma força para estruturação da transparência no município.

O que limita a atuação municipal é que os recursos são limitados, mas as necessidades são ilimitadas, o que se mostra ainda mais presente no cenário econômico atual. Há a necessidade de diminuir os gastos públicos, mas os serviços finalísticos à sociedade não podem perder qualidade e devem buscar uma abrangência suficiente para atender a maioria das demandas da população.

\subsubsection{Tecnologia}

O porte tecnológico atual da prefeitura foi observado de forma diferente para os entrevistados, onde alguns o consideraram como forte, outros como fraco, isso pode se dever ao fato da realidade com que cada um enfrenta em suas atividades.

Tendo em vista a utilização mais eficiente e os benefícios dessas mudanças, os entrevistados apresentaram a mesma concepção. Os respondentes ressaltaram que é preciso sempre buscar novas tecnologias e manter-se atualizado tanto em software como em hardware. Foi apresentado, também, que é necessário melhorar os processos internos da prefeitura, haja vista que existem muitos processos manuais, o que exige mais tempo, trabalho e dedicação. Essa foi uma das respostas obtidas que se apresentou muito importante, pois também está ligada à implementação da LAI. O responsável pelo departamento de informática considera que a implementação da LAI só se tornará efetiva quando todos os processos a ela relacionados estiverem sendo feitos de forma automatizada e eletronicamente. Um exemplo disso, é que o atual software (Governança Brasil GovBR) utilizado não atende todas essas demandas.

A atualização das informações disponibilizadas na internet depende de cada tipo de informação. Os entrevistados apresentaram que não há um prazo certo para a frequência que elas são atualizadas no portal do município, o que depende é a característica da informação. Isso foi, inclusive, uma das deficiências observadas pelo Questionário LAI Social, onde constatou-se que muitas informações não vinham sendo atualizadas.

Percebeu-se que uma das grandes dificuldades do município na implementação da LAI é a existência dos processos não automatizados no sistema, o qual vem limitando a atuação. Atualmente existem opções que podem atender a essas demandas, uma delas seria o Programa Brasil Transparente 
da CGU, que oferece apoio à implementação da LAI e ao incremento da transparência pública, além de ceder o código fonte do sistema eletrônico do Serviço de Informação ao Cidadão (e-SIC), o que poderia suprir umas das deficiências observadas quanto à transparência passiva pelo Questionário LAI Social.

Quanto ao pessoal responsável pela transparência do município, os respondentes consideram que esse pessoal tem conhecimento suficiente a respeito de tecnologia, pois para cada setor existem agentes de cargo elevado e reputação considerável para cumprir com esse encargo. Além disso, foi apresentado que o departamento de informática não atua diretamente com a LAI, no entanto, também concentra esforços para atender às demandas existentes. Assim, considera-se que existe influência desse pessoal para a implementação da LAI, pois o conhecimento sobre tecnologia é uma característica fundamental desses responsáveis.

$\mathrm{Na}$ prefeitura de Cascavel observa-se que não existe capacitação específica para a implementação e a manutenção da LAI, somente para o sistema como de forma geral.

Os entrevistados consideram que não existe necessidade de aquisição de um software especializado, que poderia se tornar um gasto desnecessário, pois eles acreditam que existe a possibilidade de adaptar o sistema atual. Apesar de os respondentes terem firmado essa posição, observa-se que existe grande deficiência para atender à transparência ativa e passiva, essa constatação corrobora com o estudo de DaMatta (2011), que também identificou que não é a falta de banco de dados que dificulta a transparência, mas sim o mau uso das informações nesse processo de divulgação. Dessa forma, poderia ser considerado novas aquisições como um investimento relevante, ou então, já fazer as adaptações necessárias no programa atual para melhorar a qualidade da transparência do município.

A tecnologia é fundamental para a implementação da LAI, tendo em vista que a sua influência é notável, sendo considerada até mesmo como a principal ferramenta para a implementação da LAI. Em Cascavel existe a necessidade de melhorar os processos internos, transformá-los para que sejam mais automatizados e eletrônicos. Além disso, uma característica importante é a integração e o compartilhamento de dados, o município ainda não atende $100 \%$.

Por meio do Questionário LAI Social observou-se grande deficiência do município para atender à transparência, uma das justificativas pode estar no fator contingencial "tecnologia". A infraestrutura atual do município não atende a todas as demandas impostas pela lei, já que existe a necessidade de aquisições de novos hardwares, de adaptações e/ou de aquisições de softwares, bem como da capacitação de pessoal. Essas características são fundamentais à implementação da LAI.

\subsubsection{Estrutura}

Verificou-se que a estrutura atual da prefeitura descreve de forma bem definida os cargos e as funções, apresentando lei própria (Lei $\left.{ }^{\circ} 3800 / 2004\right)$ que define essas características.

Quando há a necessidade de desenvolvimento de novos projetos, programas e ações normalmente obedece-se ao que está nas leis orçamentárias, existe um controle assíduo sobre novos projetos sempre que há novos gastos desse tipo são feitos os cálculos necessários para ver se o orçamento do município atenderia a esses novos custos.

Quanto à designação de um agente para implementar e/ou manter a LAI, observou-se, por meio das entrevistas, que não existe um único servidor responsável para responder aos pedidos ou implementar e/ou manter a LAI, mas há sempre um servidor responsável em cada setor, o qual busca fazer o tratamento da informação e disponibilizá-la ao usuário.

$\mathrm{Na}$ escolha de investimentos relevantes que criam despesas de capital, normalmente, busca-se observar sempre o que está prescrito no PPA, os quais utilizam critérios técnicos e políticos. Um investimento relevante, como por exemplo a implementação da LAI, deve ser considerado no PPA do município, para isso se faz necessário um planejamento adequado e que seja interesse da administração pública para incluir nesse instrumento de gestão pública.

Os entrevistados consideram que a atual estrutura do município atende suficientemente a LAI, pois as funções são bem distribuídas, já que existem diversos setores e para cada setor existe um agente superior que busca atender às demandas da LAI.

Portanto, a estrutura foi considerada como uma variável que não influencia a implementação da 
LAI no município de Cascavel, de acordo com o entendimento dos entrevistados. No entanto, esses resultados poderiam ser diferentes em outros municípios, o que até mesmo poderia ser considerado em novas pesquisas. Normalmente, a designação de servidores para atender a LAI é feita para aqueles agentes que já estão inseridos na administração pública, tornando-se apenas mais uma função para os selecionados. Essa é uma preocupação observada nos resultados de DaMatta (2011), a falta de pessoal qualificado, destinado exclusivamente para a manutenção do atendimento de solicitações e de aspectos contingencial da transparência. $\mathrm{O}$ que se mostrou evidente nas entrevistas, foi o fato de que os entrevistados consideraram o modelo de gestão muito engessado, o que impediria inovações e mudanças significativas.

\subsubsection{Estratégias}

As estratégias adotadas pela prefeitura para atender aos diversos tipos de demandas estão direcionadas à preocupação em gastar bem os recursos públicos. No entanto, foi colocado pelos entrevistados que existe a necessidade de estar desburocratizando a máquina pública, ou seja, é preciso modernizar-se, diminuir o número de papéis e transformar os processos mais eletrônicos, o que a tornaria, então, mais ágil e mais eficiente.

Os respondentes colocaram que não há estratégias voltadas para a implementação da LAI, percebeu-se que os objetivos são de atender aos dispositivos da lei da melhor forma possível. Isso poderia ser uma justificativa a respeito da deficiência observada na transparência ativa e passiva do município. Ainda não foram apresentadas ideias ou estratégias voltadas para implementar a LAI. Dessa forma, há a necessidade de que o interesse público concentre esforços para adotar estratégias ou políticas públicas voltadas à implementação da LAI.

Por fim, no fator contingencial "estratégias", se faz necessário o interesse público, o qual poderá ser evidente em futuros planos de gestão a partir do desenvolvimento do município e da LAI. Uma das principais críticas se referem ao modelo atual de gestão, o qual ainda se encontra muito preso à burocracia, não tendo ampla liberdade na atuação dos gestores públicos, limitando o surgimento de mudanças e de inovações. Existe a necessidade, portanto, de partir ainda mais para o modelo gerencial e de aproximar o órgão público do interesse da sociedade, como, por exemplo, cidadãos, contribuintes e clientes.

\subsubsection{Porte}

O município de Cascavel tem uma população estimada de 312.778 habitantes em 2015. Sua arrecadação também é considerada relativamente alta para o município. Dessa forma, Cascavel tem um porte considerado alto, não sendo um município com baixo número de habitantes e tendo sua arrecadação representativa.

Conforme foi avaliado pelos entrevistados, eles acreditam que quanto maior o porte de um município, maior é o seu trabalho, no entanto, apresenta mais recursos, tanto pessoal quanto de infraestrutura para atender a toda essa demanda. Municípios de menor porte apresentam menos trabalho, o que, de certa forma, facilita o seu desempenho. Isso afeta, por exemplo, as aquisições, as demandas da população e a tecnologia utilizada. Apesar de os municípios de menor porte apresentarem menos trabalho, também apresentam menos recursos e servidores. Dessa forma, é importante levar em conta a realidade de cada município e suas demandas.

Os respondentes acreditam que um porte diferenciado poderia sim afetar a implementação da LAI. Um município com maiores recursos normalmente terá uma disponibilidade de valores maior para investir nessa implementação. Já os municípios menores sofrem com carência de pessoal, de softwares necessários e de infraestrutura adequada.

Considerando o porte de um município, este não pode escolher o porte que prefere ter. Assim, é importante que os gestores públicos observem as melhores práticas para se adaptar a cada realidade existente. Essa variável afeta, sim, a implementação da LAI, no entanto ela não pode ser controlável. 


\section{CONCLUSÃO}

Essa pesquisa teve como objetivo geral avaliar as ações adotadas pela gestão pública municipal ao efetivo cumprimento da Lei de Acesso à Informação, quanto à Transparência Ativa e Passiva, sob a abordagem da Teoria Contingencial. Sendo que buscou-se discutir as concepções da LAI, da transparência e da Teoria Contingencial, além do fato de que buscou-se identificar e analisar como os gestores púbicos estão abordando e cumprindo essa Lei, em que se visou, também, observar como os fatores contingenciais afetam a implementação da LAI no município.

Concluiu-se que o município não vem cumprindo as disposições da lei, uma vez que mostra-se deficiente, principalmente na transparência passiva, sendo que ainda é necessário desenvolver melhor a concepção da transparência ativa. Apesar de já haver informações dispostas no portal eletrônico do município, ainda não se atende aos parâmetros de boa informação, sendo que uma das justificativas que pode ser observada pela Teoria Contingencial foi a falta de estratégias e de tecnologias adequadas para atender à implementação da LAI.

O interesse público é fundamental para atender às demandas da LAI, para elaborar estratégias específicas para dar suporte ao desenvolvimento da lei, de modo que seja possível estar utilizando as tecnologias necessárias a essa implementação, tanto em hardware como em software. O programa Brasil Transparente, criado pela Controladoria Geral da União, pode ser uma das sugestões para implementar a LAI, haja vista que ele oferece apoio à implementação da lei e ao incremento da transparência pública por meio da capacitação, da disponibilização do sistema e-SIC, da orientação sobre a lei e do suporte necessário.

Ficou evidente que a transparência é característica notável dos novos modelos de gestão, para tanto é necessário se desvincular ainda mais das características burocráticas de gestão e se aproximar do modelo atual, o gerencial. A Teoria Contingencial explica que não há nada de absoluto nas organizações, tudo depende de tudo e tudo é relativo, para isso as variáveis ambiente, tecnologia, estrutura, estratégias e porte devem ser consideradas na implementação da LAI.

A prefeitura do município de Cascavel ainda não desenvolve estratégias específicas para atender à LAI, no entanto ela busca observar, na medida do possível, as exigências dessa lei. A gestão municipal busca concentrar esforços na automatização dos processos de acesso à informação, de modo que a transparência ativa seja mais evidente, o que facilita o direito dos cidadãos e também diminui a carga de trabalho com os pedidos de informação.

O município de Cascavel ainda não cumpre de forma efetiva e suficiente os requisitos mínimos da Lei $\mathrm{n}^{\circ}$ 12.527/2011. No ranking disponibilizado pelo TCE/PR (2014), de uma amostra de 69 municípios, Cascavel ficou classificada em $35^{\circ}$, apresentando um percentual de $28,02 \%$, o que é considerado, portanto, deficiente, que ainda precisa ser melhorado, tanto na transparência ativa como na passiva.

Portanto, ficou claro que as variáveis ambiente e porte não são controláveis, sendo necessário ações de cada município para se adaptarem a sua realidade. Os fatores tecnologia e estratégia também se mostraram importantes no entendimento do responsável pelo departamento de informática e pelo controle interno, tendo em vista que são variáveis que podem ser controladas pela prefeitura do município e fundamentais para que ocorra a implementação da LAI.

Já a variável estrutura, também considerada controlável, teve sua importância questionada na entrevista, pois a implementação da LAI foi tida como indiferente à estrutura do município no que se refere ao plano de cargos e de carreiras. No entanto, pela experiência do presente pesquisador, por ter participado, também, do projeto LAI SOCIAL, a estrutura é um fator a ser considerado, e essa consideração pode ser efetuada em pesquisas futuras.

É importante observar que essa pesquisa ficou limitada ao município de Cascavel e, dessa forma, uma amostra diferente poderia trazer outros resultados, até mesmo os sujeitos entrevistados teriam outras contribuições para acrescentar. Além disso, como essa pesquisa teve início em 2014 e conclusão em 2015, a realidade do município quanto à transparência já é outra, onde, inclusive, foi regulamentado por meio do Decreto n. ${ }^{\circ} 12.750$, de 02 de fevereiro de 2016.

Dessa forma, a proposição de pesquisa pode ser comprovada parcialmente por meio desse 
estudo. O município de Cascavel não cumpre, de forma efetiva, com as exigências da lei, principalmente nos aspectos relacionados à transparência passiva, no entanto, isso ocorre devido às defíciências contingenciais tecnologia e estratégias, e não à estrutura organizacional.

Recomenda-se como sugestão de pesquisa a elaboração de outros trabalhos relacionados à transparência sob a abordagem contingencial em municípios distintos, bem como sobre o desenvolvimento da LAI desde 2011 até os momentos atuais na União, nos Estados e nos Municípios.

Essa pesquisa acrescenta, ainda, outros questionamentos. A que medida, hoje, as administrações públicas municipais estão se adaptando ao novo modelo de administração gerencial tendo em vista os novos paradigmas do empreendedorismo governamental aplicado ao setor público? Como as estratégias dos gestores públicos e as tecnologias de informação e comunicação podem modificar a realidade do município? Os municípios estão preparados para se mostrarem transparentes, ainda mais em um momento de perda de credibilidade política? Esses questionamentos demonstram a importância do tema e como ele está inserido no nosso cotidiano, perguntas que remetem à cientificidade do tema e à abertura para novos temas de pesquisa.

A transparência visa aperfeiçoar o Estado Democrático de Direito tornando mais clara a atuação dos gestores públicos tanto em âmbito municipal como federal, garantindo um direito já exposto no art. $5^{\circ}$, XXXIII, da Constituição Federal de 1988. Além disso, busca um novo modelo de gestão pública, o gerencial, que torna a atuação pública mais eficiente e eficaz, aperfeiçoando ainda mais a participação dos cidadãos na gestão da máquina pública.

\section{REFERÊNCIAS}

Alves, M. S. D. (2012). Do sigilo ao acesso: análise tópica da mudança de cultura. Revista do Tribunal de Contas do Estado de Minas Gerais, Minas Gerais, 1, 120-134.

Chiavenato, I. (1979). Novas abordagens na teoria administrativa. Revista de Administração de Empresas, 19(2), 27-42.

Chiavenato, I. (2004). Introdução a Teoria Geral da Administração (7a ed.). São Paulo: Elsevier.

Chiavenato, I. (2012). Administração Geral e Publica (3a ed.). Barueri, SP: Manole.

Constituição da República Federativa do Brasil de 1988. (1998). Brasília. Recuperado em 26 dezembro 2016, de

https://www.planalto.gov.br/ccivil_03/constituicao/constituicaocompilado.htm

Controladoria Geral da União (2013) Rumo a uma Cultura de Acesso à Informação: a Lei 12.527/2011, módulo 2, Escola Virtual da CGU.

Cruz, C. F., Silva, L. M., \& Santos, R. (2010). Transparência da gestão fiscal: um estudo a partir dos portais eletrônicos dos maiores municípios do Estado do Rio de Janeiro. Contabilidade, Gestão e Governança, 12(3), 102-115.

DaMatta, R. (2011). Pesquisa Diagnóstico sobre Valores, Conhecimento e Cultura de

Acesso à Informação Pública no Poder Executivo Federal Brasileiro. Controladoria Geral da União. 2011. Recuperado em 26 dezembro 2016, de http://goo.gl/cOKclu

Espejo, M. M. D. S. B. (2008). Perfil dos atributos do sistema orçamentário sob a perspectiva contingencial: uma abordagem multivariada. Tese de doutorado, Universidade de São Paulo, São Paulo, SP, Brasil.

Guerra, A. R. (2007). Arranjos entre fatores situacionais e sistema de contabilidade gerencial sob a ótica da teoria da contingência. Tese de doutorado, Universidade de São Paulo, São Paulo, SP, Brasil. 
Junqueira, E. (2010). R. Perfil do sistema de controle gerencial sob a perspectiva da teoria da contingência. Dissertação de mestrado, Universidade de São Paulo, São Paulo, SP, Brasil.

Lei n. 12.527, de 18 de novembro de 2011 (2011). Regula o acesso à informação previsto na Constituição Federal. Diário Oficial República Federativa do Brasil. Brasília, DF, 18 nov. 2011.

Recuperado em 26 dezembro 2016, de http://www.planalto.gov.br/ccivil_03/_ato20112014/2011/lei/112527.htm

Mintzberg, H. (1995). Criando organizações eficazes (2a ed.). São Paulo: Atlas.

Molinari, S. K., \& guerreiro, R. (2004). Teoria da contingência e contabilidade gerencial: um estudo de caso sobre o processo de mudança na controladoria do Banco do Brasil. In Congresso USP de Controladoria e Contabilidade, São Paulo, SP, Brasil, 4.

OCDE. (2002). O cidadão como parceiro: manual da OCDE sobre informação, consulta e participação na formulação de políticas públicas [Manual]. Brasília: MPOG.

Paiva, C. P., \& Zuccolotto, R. (2009). Índice de transparência fiscal das contas públicas dos municípios obtidos em meios eletrônicos de acesso público. In ENCONTRO DA ANPAD, São Paulo, SP, Brasil, 33.

Paraná. Tribunal de Contas do Estado. (2014). Relatório de auditoria social: projeto LAI Social. Curitiba: Tribunal de Contas do Estado do Paraná.

Porter, M. E. (1986). Estratégia competitiva: técnicas para análise de indústrias e da concorrência (15a ed.). São Paulo: Campus.

Queiroz, M. I. P. D. (1988). Relatos orais: do "indizível” ao “dizível”. In SIMSON, O. M. (org. e intr.). Experimentos com histórias de vida (Itália-Brasil). São Paulo: Vértice.

Richardson, R. J., \& Peres, J. A. (1985). Pesquisa social: métodos e técnicas (1a ed.). São Paulo: Atlas.

Stiglitz, J. (1999). On Liberty, the Right to Know, and Public Disclosure: The Role of Transparency in Public Life.ll Oxford Amnesty Conference.

Trivinos, A. N. S. (1995). Introdução à pesquisa em ciências sociais: a pesquisa qualitativa em educação: o positivismo; a fenomenologia; o marxismo (4a ed.) São Paulo: Atlas.

Yin, R. K. (2002). Estudo de Caso: Planejamento e Métodos (2a ed.). Porto Alegre: Bookman. 